\title{
Analysis of Benzoic Acid in Quasi-Drug Drink Using Isotope Dilution Liquid Chromatography Mass Spectrometry
}

\author{
Insun Lee, ${ }^{\dagger, \ddagger}$ Seonghee Ahn, ${ }^{+, *}$ Byungjoo Kim,${ }^{\dagger}$ Eujin Hwang, ${ }^{\dagger}$ and Yong Seong Kim ${ }^{\ddagger}$ \\ ${ }^{\dagger}$ Division of Metrology' for Quality Life, Korea Research Institute of Standards and Science, Yuseong, Daejeon 305-600, Korea \\ ${ }^{*} E$-mail: sahn@ikriss.re.kr \\ ${ }^{\ddagger}$ Department of Chemistiy, KyngNom University, Masan, Kyungnam 631-701, Korea \\ Received May 22, 2008
}

\begin{abstract}
An analytical method was developed for the accurate determination of benzoic acid in commercial quasi-dng drinks using isotope dilution liquid chromatography mass spectrometry (ID-LC/MS). Sample drinks were spiked with ${ }^{13} \mathrm{C}_{6}$-benzoic acid and these mixtures were cleaned by a nylon membrane filter. The sample mixtures were then analyzed using LC/Tandem MS in the negative ion mode without further clean-up or extraction steps. For the chromatographic separation, a C18 column with isocratic mobile phase of $50: 50(\mathrm{v} / \mathrm{v})$ anmorium acetate buffer at $\mathrm{pH} 4.5$ and methanol mixture was used. MS was operated with electrospray ionization in the negative mode. Benzoic acid and its isotope analogue were detected by selectively monitoring the collisionally-induced dissociation channels of $[\mathrm{M}-\mathrm{H}]^{-} \rightarrow\left[\mathrm{M}-\mathrm{CO}_{2} \mathrm{H}\right]^{-}$at $\mathrm{m} / \mathrm{z} 121 \rightarrow 77$ and $\mathrm{m} / \mathrm{z} 127 \rightarrow 83$, respectively. Repeatability and reproducibility studies showed that the ID-LC/MS/MS method is a reliable and reproducible method which can provide less than $0.3 \%$ of relative standard deviation (RSTD) of method precision for analysis of benzoic acid.
\end{abstract}

Key Words : Isotope dilution liquid chromatography mass spectrometry (ID-LC/MS), LC/tandem MS, Lncertainty

\section{Introduction}

Food preservation has been of great importance nowadays with the increase in production of processed and convenience foods. Preservatives inhibit yeast, microbial and molds growth in foods and beverages. Various classes of preservatives are used, depending on the food products and the expected microorganisms. Benzoic acid is one of the most commonly used preservatives in numerous foodstuffs such as soft drink, fruit juice, margarine, yoghurt, fruit jams and cheeses. ${ }^{1-3}$

Despite of the widespread use and effectiveness of benzoic acid, it has been reported that metabolic acidosis, convulsions, and hyperpnoea were observed in experimental animals and human given very high doses. ${ }^{4.5}$ In other studies, allergic reactions of benzoate were observed in human. ${ }^{6}$ Additionally, it was issued that benzene which has been known as a carcinogenic compound ${ }^{7}$ was detected in vitamin $\mathrm{C}$ drinks containing benzoic acid. It was reported that benzene was produced by decarboxylation of benzoic acid in the presence of ascorbic acid. ${ }^{8}$ Therefore, it has been recommended not to add benzoic acid in vitamin $C$ drinks. These preservatives are allowed by legislation that establishes the maximum permitted concentrations in each type of food. For example, in soft drinks, European Union legislation establishes the limit of $150 \mathrm{mg} / \mathrm{kg}$, Australia, 400 $\mathrm{mg} / \mathrm{kg}$, and Korea, $600 \mathrm{mg} / \mathrm{kg}$, respectively. The acceptable daily intake (ADI) for benzoic acid is $5 \mathrm{mg} / \mathrm{kg}$ body weight. ${ }^{2}$ It is, therefore, important to develop a method for the accurate determination of benzoic acid in foodstuffs.

There are a variety of analytical methods for the analysis of benzoic acid in food stuffs. The majority of these are separation methods such as thin-layer chromatography (TLC), high performance liquid chromatography (HPLC), ${ }^{1 j-15}$ gas chromatography (GC) or gas chromatography mass spectrometry (GC/MS) ${ }^{16-18}$ and capillary electrophoresis (CE) ${ }^{19-22}$ However, these methods used complicated and labor intensive pre-treatment procedures such as steam distillation steps, solid phase extraction and derivatization steps. HPLC with an UV detector has been most widely used for the analysis of benzoic acid due to its high sensitivity. However, UV detection can be easily interfered by sample matrices or contaminants, causing biases in the measurement results. In this respect, ID-LC/MS is a promising candidate as a reference method ${ }^{3-26}$ for the accurate determination of benzoic acid as the mass spectrometric detection providing one or two more stages of selectivity for the analyte and the introduction of the isotope analogue as an internal standard overcomes difficulty of correcting recovery yield in sample preparation and separation.

The objective of this work is to develop a definitive reference method for the deternination of benzoic acid using isotope dilution liquid chromatography mass spectrometry (IDLC/MS). The conditions of separation and electrospray ionization efficiency had to be optimized considering the $\mathrm{pKa}$ of benzoic acid (pKa: 4.2). Additionally, sample preparation processes were simplified to a single stage of membrane filtering without further procedures. Using $\mathrm{D}-\mathrm{LC} / \mathrm{MS}$ method, commercial drinks were analyzed. The accuracy, repeatability, and reproducibility of the method were also evaluated if the method provides adequate metrological quality.

\section{Experimental}

Materials. Benzoic acid (99.999\%) was purchased from the National Institute of Standard and Technology (Gaithersburg, MD, USA) and used without any fiurther purification. 
Purity assay was carried out by a manufacturer and that result indicates a purity of $0.999996 \mathrm{~mol} / \mathrm{mol}$ by mass spectrometric and coulometric measurements. ${ }^{13} \mathrm{C}_{6}$-benzoic acid $(98 \%)$ was purchased from Cambridge Isotope Laboratories (Andover, MA, USA). HPLC grade methanol was obtained from Burdick and Jackson (Muskegon, MI, USA) and pure water was prepared by using a membrane-filtering system and further purified by passing through a Millipore Corp. Milli-Q RG purification system. Ammonium acetate was from Aldrich (Milwaukee. WI, USA) and formic acid was from Fluka (Steinheim, Germany).

Standard solution. Standard solutions were prepared and verified in our laboratory. The procedure for preparation and verification was described elsewhere.$^{26-28}$ Briefly, four benzoic acid standard solutions were gravimetrically prepared in water at the level of $100 \mathrm{mg} / \mathrm{kg} \cdot \mathrm{A}^{13} \mathrm{C}_{6}$-benzoic acid standard solution was prepared in the same way. For each of four benzoic acid standard solutions, two isotope ratio standards with $1: 1$ isotope ratio were prepared by gravimetrically mixing the standard solution with the ${ }^{13} \mathrm{C}_{6}$-benzoic acid standard solution. We tested self-consistency within and among the standard solutions by inter-comparing the eight isotope ratio standards by LC/MS. Based on the inter-comparing results, repeatability and reproducibility of preparing standard solutions and isotope ratio standards were evaluated and one isotope ratio standard was selected and used for further sample analysis

Sample preparation. Quasi-drug drinks were obtained from a local market. $1 \mathrm{~g}$ of subsample was spiked with an appropriate amount of the ${ }^{13} \mathrm{C}_{6}$-benzoic acid standard solution to make $1: 1$ isotope ratio and then filtered by using a nylon membrane filter (Waters Corp. Clifton, NJ, USA). The sample was then analyzed by LC/MS without further cleanup or extraction procedures. For the validation of our method. we prepared samples with known levels of benzoic acid by fortifying blank samples, which were also obtained from local markets and tested that their benzoic acid levels were below the detection limit of this method, by gravimetrically adding a stock solution of benzoic acid.

LC/MS Analysis. API 2000 mass spectrometer from Applied Biosystems (Forster City, CA, USA) which is interfaced with an 1100 Series LC system from Agilent Technologies (Palo Alto, CA, USA) was used in this study. Samples prepared as described above and the isotope ratio standard were injected onto a Waters Corp. (Milford, MA, USA) Symmetry $\mathrm{C} 18(150 \mathrm{~mm}$ length, $2.1 \mathrm{~mm}$ i.d., $3.5 \mu \mathrm{m}$ particle size) with a guard column. Analytical separation was performed using an isocratic $50: 50$ mixture of $5 \mathrm{mM}$ ammonium acetate buffer $(\mathrm{pH} 4.5)$ and methanol at the flow rate of $0.2 \mathrm{~mL} / \mathrm{min}$. The mass spectrum was obtained with the negative ion mode at the optimized spray conditions. For the IDMS analysis, MS was operated on both a selected ion monitoring (SIM) mode and a selected reaction monitoring (SRM) mode. The SIM mode monitored the $[\mathrm{M}-\mathrm{H}]^{-}$ions of benzoic acid and ${ }^{13} \mathrm{C}_{6}$-benzoic acid at $\mathrm{m} / \mathrm{z} 121$ and 127 . respectively. On the other hand. the SKM mode used the collision induced dissociation (CID) channels providing [M-
$\mathrm{CO}_{2} \mathrm{H}^{-}$ions of benzoic acid and its isotope analogue at $\mathrm{m} / \mathrm{z}$ $121 \rightarrow 77$ and $\mathrm{m} / \mathrm{z} 127 \rightarrow 83$, respectively. For the SRM mode, the collision cell, the second quadrupole of the mass spectrometer, was filled with nitrogen gas at a pressure of $\sim 0.2 \mathrm{~Pa}\left(-0.2 \times 10^{-3} \mathrm{mbar}\right)$ and the collision energy was $-16 \mathrm{eV}$.

\section{Results}

LC/MS of benzoic acid. The mass spectra of benzoic acid and ${ }^{13} \mathrm{C}_{6}$-benzoic acid in water were obtained using the negative ionization mode of electrospray as shown in Figure 1 (a) and (b). [M-H] peaks of benzoic acid at $\mathrm{m} / \mathrm{z} 120.9$ and ${ }^{13} \mathrm{C}_{6}$-benzoic acid at $\mathrm{m} / \mathrm{z} 126.9$ were dominant in the corresponding spectra. Weak $\left[\mathrm{M}-\mathrm{CO}_{2} \mathrm{H}\right]^{-}$ion peaks at $\mathrm{m} / \mathrm{z}$ 77 and 83 , which were due to the post source decay of [M$\mathrm{H}^{-}$ions, were also observed. The tandem mass spectra by collisionally induced dissociation (CID) of $[\mathrm{M}-\mathrm{H}]^{-}$ions of benzoic acid and ${ }^{13} \mathrm{C} 6$-benzoic acid are shown in Figure 1(c) and (d). In both spectra, $\left[\mathrm{M}-\mathrm{CO}_{2} \mathrm{H}\right]^{-}$ions were observed at $\mathrm{m} / \mathrm{z} 77$ for benzoic acid and at $\mathrm{m} / \mathrm{z} 83$ for ${ }^{13} \mathrm{C}_{6}$-benzoic acid. Because no other fragment ions were observed in the $\mathrm{CD}$ spectrum, $[\mathrm{M}-\mathrm{H}]^{-} \rightarrow\left[\mathrm{M}-\mathrm{CO}_{2} \mathrm{H}\right]^{-}$ions were selected as CID channels for the detection of both benzoic acid and ${ }^{13} \mathrm{C}_{6-}$ benzoic acid in the SRM mode.

LC separation conditions were optimized considering the $\mathrm{pKa}$ of benzoic acid. As the pKa of benzoic acid is 4.2, the retention time and separation efficiency were observed at the various $\mathrm{pH}$ levels of the mobile phase and the flow rate. The isocratic 1:1 mixture of ammonium acetate buffer $(\mathrm{pH} 4.5)$ and methanol was chosen as it provides an appropriate retention time and separation performance without losing ionization efficiency of the analyte in the negative ion mode. Figure 2 shows that the chromatogram of the isotope ratio standard (a) and a drink sample (b) in the SIM mode (i) and the SRM mode (ii). The chromatograms were dominated by the peaks of the target analytes and showed low background

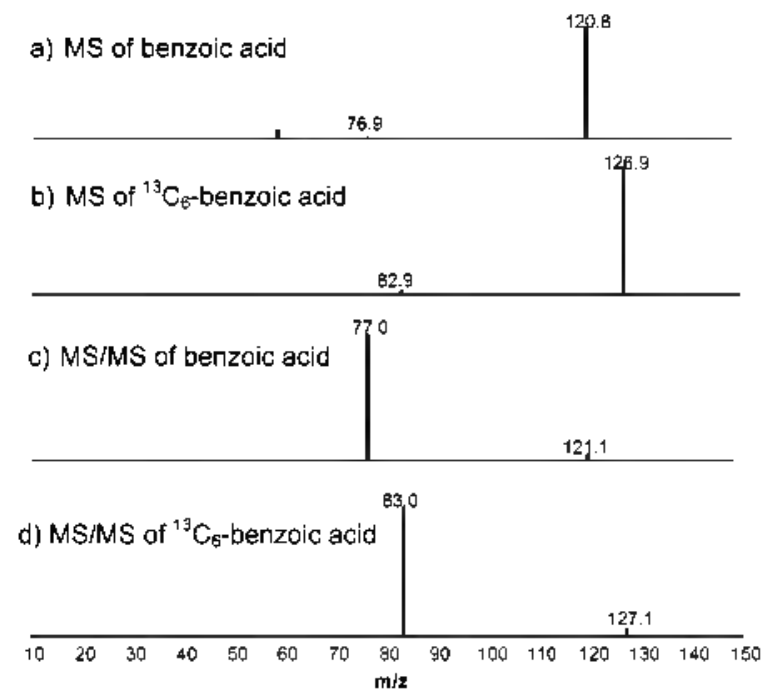

Figure 1. MS spectra of $5 \mathrm{ppm}$ benzoic acid (a) and ${ }^{13} \mathrm{C}_{6}$-benzoic acid (b) in water and MS/MS spectra by collisionally induced dissociation of benzoic acid (c) and ${ }^{13} \mathrm{C}_{6}$-benzoic acid (d). All spectra were obtained in negative ionization mode. 


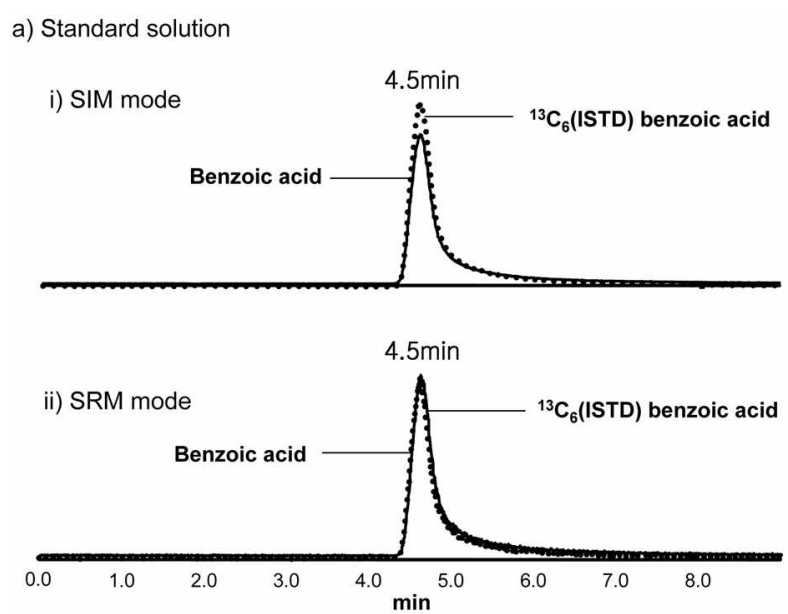

b) Quasi-drug drink solution
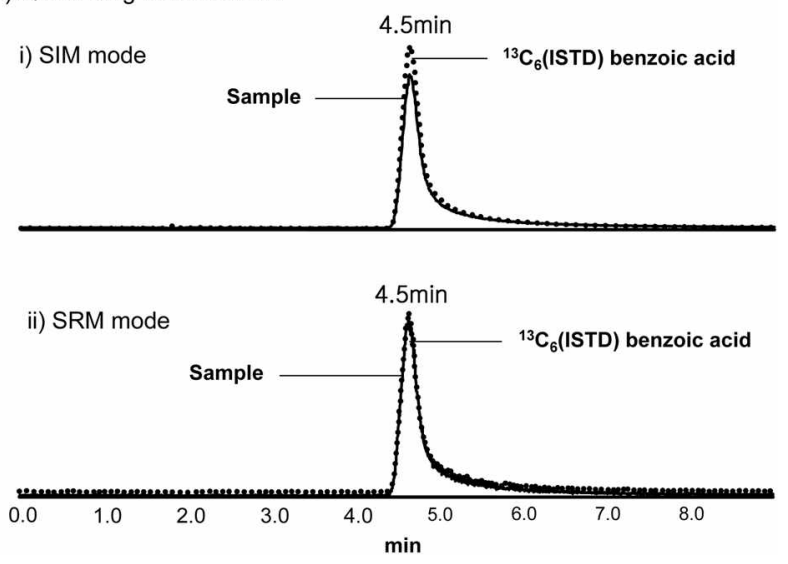

Figure 2. Typical LC/MS of single ion monitoring mode (SMM) (i) and LCMS/MS of selected reaction monitoring mode (SRM) (ii) chromatogram of benzoic acid and ${ }^{13} \mathrm{C}$-benzoic acid for the standard mixture solution (a) and the quasi-dnug drink (b). respectively. The concentration of the standard mixture solution was 80 ppm and that of the quasi-drug drink solution was 50 ppm. For SIM mode, $\mathrm{m} / \mathrm{z} 12 \mathrm{l}$ for benzoic acid and $\mathrm{m} / \mathrm{z} 127$ for ${ }^{13} \mathrm{C}_{6}$-benzoic acid were detected and for SRM mode. $\mathrm{mz} \mathrm{I} 2 \mathrm{I} \rightarrow 77\left[\mathrm{M}-\mathrm{CO}_{2} \mathrm{H}\right]^{-}$for benzoic acid and $\mathrm{m} / \mathrm{z} 127 \rightarrow 83\left[{ }^{13} \mathrm{C}_{6}-\mathrm{M}-\mathrm{CO}_{2} \mathrm{H}\right]^{-}$was selected for CID channels, respectively.

noise and no significantly interfering peaks from sample matrix. With those LC/MS conditions, the limits of detection for a signal-to-noise ratio of 3 were $0.05 \mathrm{ppm}$ for SIM mode and $1.0 \mathrm{ppm}$ for SRM mode, respectively. Even though the recovery results of the SIM mode are not much different from those of the SRM mode (data not shown), the SRM mode was operated for the quantitative analysis of IDMS measurement. Because only the tiltration step was performed for sample preparation, it is possible for the SIM mode to be interfered by sample matrix.

Validation of method. There are a number of ingredients, such as carbohydrates and minerals, in commercial quasidrug drinks which might interfere with the detection of benzoic acid; therefore the recoveries of benzoic acid from variously fortitied samples were investigated. The blank drink has similar ingredients as those of the sample drink but does not include benzoic acid. The blank drink was confirmed by mass spectrometry that the level of benzoic acid was
Table 1. Recovery test results with gravimetrically fortified samples

\begin{tabular}{|c|c|c|c|}
\hline & $\begin{array}{c}\text { Fortified } \\
\text { concentration } \\
(m g / k)\end{array}$ & $\begin{array}{c}\text { Experiment } \\
\text { concentration } \\
(\mathrm{mg} / \mathrm{kg})\end{array}$ & $\begin{array}{c}\text { Recovely } \\
(\%)\end{array}$ \\
\hline Sample 击l & 48.83 & 49.25 & 100.85 \\
\hline Sample H2 & 132.41 & 131.99 & 99.68 \\
\hline Sample 此3 & 201.59 & 199.94 & 99.18 \\
\hline Sample & 376.25 & 375.33 & 99.76 \\
\hline Sample $\$ 5$ & 668.59 & 671.04 & 100.37 \\
\hline Sample 莽6 & 751.86 & 746.40 & 99.27 \\
\hline
\end{tabular}

below the detection limit of the LCMS method. Samples with various levels of benzoic acid were prepared by fortifying the blank drink by gravimetrically spiking a benzoic acid stock solution and analyzed by the ID-LC/MS method. Table 1 shows that the recovery of fortified benzoic acid was over $99 \%$ through the benzoic acid level tested, indicating that matrix in commercial drinks do not seriously affect on the determination of benzoic acid by the ID-LCMS .

To test repeatability and reproducibility of the analytical method, it is necessary to perform experiments with highly homogenized reference materials. Our laboratory as the metrology institute of Korea has experiences in producing several classes of certified reference materials and applied these techniques for preparing a homogenized reference material for the validation of this method. The procedure of preparation for the reference material is briefly described here. ${ }^{26-28}$ More than $6,000 \mathrm{~mL}$ of drinks were collected in one big bottle, and then homogenized using a shaker for hours and bottled into a $200 \mathrm{~mL}$-polyethylene jar. The jar was purged with argon, tightly sealed with a Teflon lined cap and stored at $4{ }^{\circ} \mathrm{C}$. Repeatability was tested that multiple bottles were taken and analyzed by the LCMS/MS. Reproducibility was tested by carrying out the same repeatability test after a reasonable time interval of weeks to months - for this study, the experiments have been performed after 5 months. The results are listed in the Table 2 . The relative standard deviation of the results obtained from the ID-LC/

Table 2. Results of benzoic acid in quasi-dnug drink by ID-LC/MS/ MS in the SRM mode in two different time periods within 5 months

\begin{tabular}{ccc}
\hline & \multicolumn{2}{c}{ Results of ID-LCMS/MS $(\mathrm{mg} / \mathrm{kg})$} \\
\hline & Subsample $\# 1-1$ & 247.02 \\
& Subsample $\# 1-2$ & 248.23 \\
& Subsample $\# 1-3$ & 248.53 \\
Period 1 & Subsample $\# 1-4$ & 248.96 \\
& Subsample $+1-5$ & 248.21 \\
& Average & 248.14 \\
& RSTD & $0.69(0.30 \%)$ \\
& Expanded uncertainty & $2.98(1.2 \%)$ \\
\hline & Subsample \#2-1 & 251.30 \\
Period 2 & Subsample $\# 2-2$ & 253.06 \\
& Subsample \#2-3 & 255.16 \\
& Average & 253.18 \\
& RSTD & $1.93(0.76 \%)$ \\
& Expanded uncertainty & $12.15(4.8 \%)$ \\
\hline
\end{tabular}

"The expanded uncertainties are with a level of confidence of $95 \%$. 
Table 3. Lncertainty sources in the D-LC/MSMS for the detemination of benzoic acid in quasi-drug drinks

\begin{tabular}{|c|c|c|}
\hline & $\begin{array}{l}\text { Sources } \\
\text { (Evaluation Methods) }\end{array}$ & $\begin{array}{l}\text { Typical value } \\
\text { (Relative \%) }\end{array}$ \\
\hline \multirow[t]{2}{*}{ Benzoic acid standard solution } & Purity of the reference material (from the certificate) & $0.0001 \%$ \\
\hline & $\begin{array}{l}\text { Gravimetric preparation (from cross-check of independent } \\
\text { sets of calibration solutions) }\end{array}$ & $0.32 \%$ \\
\hline Calibration standard mixture & $\begin{array}{l}\text { Gravimetric mixing (from cross-check of independent } \\
\text { sets of calibration standard mixtures) }\end{array}$ & $0.35 \%$ \\
\hline Weights of sample taken for analysis & $\begin{array}{l}\text { Readability and linearity of the balance used } \\
\text { (from the certificate of the balance) }\end{array}$ & $<0.01 \%$ \\
\hline $\begin{array}{l}\text { Weights of }{ }^{13} \mathrm{C}_{6} \text {-benzoic acid solution spiked } \\
\text { into sample taken for analysis }\end{array}$ & $\begin{array}{l}\text { Readability and linearity of the balance used } \\
\text { (from the certificate of the balance) }\end{array}$ & $<0.01 \%$ \\
\hline $\begin{array}{l}\text { Peak area ratio of benzoic acid and }{ }^{1} \mathrm{C}_{6} \text {-benzoic acid from } \\
\mathrm{LC} / \mathrm{MS} / \mathrm{MS} \text { measurements of calibration standard solution }\end{array}$ & Staudard deviation of multiple measurements & $0.10 \%$ \\
\hline $\begin{array}{l}\text { Peak area ratio of benzoic acid and }{ }^{1} \mathrm{C}_{6} \text {-benzoic acid } \\
\text { from LC/MSMS measurements of sample extract }\end{array}$ & Standard deviation of multiple measurements & $0.30 \%$ \\
\hline
\end{tabular}

MS method with the SRM mode within a time period ranges between $0.30 \%$ and $0.76 \%$, indicating that the method has an excellent repeatability. The measurement values from the two period agree to each other within their uncertainties. indicating that the method provide a good reproducibility.

Sources of uncertainty. Uncertainty sources of results from the ID-LC/MS/MS method are listed in the Table 3. Purity of the reference material provided from its certificate works as a systematic uncertainty throughout this study. Standard deviation of measurement results of multiple subsamples within a time period in this case represents the random uncertainty due to the uncertainties in weighing sample taken for analysis, weighing the amount of the ${ }^{13} \mathrm{C}_{6-}$ benzoic acid solution spiked to the sample, and the LC/MS/ MS measurements of the isotope ratio standards and sample extracts. The uncertainties in the standard solution and the isotope ratio standard mixture do not involve in the variation of results of subsamples within a period and give systematic effects on the results. The reproducibility also includes the uncertainties in the gravimetric preparation of the standard solution and the isotope ratio standards as well as the random uncertainty sources of the repeatability test in a single period. Therefore, all the uncertainty sources but the uncertainty of the purity of the benzoic acid reference material is included in the reproducibility as random effects. All combined uncertainty using ID-LC/MS/MS for benzoic acid analysis is $1.2 \%$ with $95 \%$ confidence level.

\section{Conclusions}

The LC/tandem-MS based on the isotope dilution mass spectrometric method has been developed for the determination of benzoic acid in quasi-drug drink. For the validation of the method, gravimetrically fortified samples were analyzed by $\mathrm{D}-\mathrm{LC} / \mathrm{MS} / \mathrm{MS}$. The analytical results agree with the gravimetrically prepared values within their uncertainties. Repeatability and reproducibility test was also carried out. The test results proved that ID-LC/MS/MS using the negative ion mode for determination of benzoic acid has a metrological quality less than $1.2 \%$ with $95 \%$ confidence.

\section{References}

1. Mota, F. J. M.; Ferreira, I. M. P. L. V. O.; Cunha, S. C.; Beatrix, M.: Oliveira, P. P. Food Chem. 2003, 8z, 469.

2. Tfouni, S. A. V.; Toledo, M. C. F. Food Control. 2002, /3, 117.

3. Garcia, I.; Ortiz, M. C.; Sarabia, L.; Vilches, C.; Gredilla, E. $J$. Chromatogr: A 2003, 992, 11

4. WHO Technical Repont Series $1997,868$.

5. Quick, A. J. J. Biol. Chem. 1931, 92,65.

6. Hanuksela, . M.; Haahtela, T. Allergr 1987, 42, 561.

7. Maltoni, C.; Scarnato, C. Med. Lenoro 1979, 70, 352.

8. Gardner, L. K.; Lawrence, G. D. J. Agri. Food Chent 1993, 41, 693.

9. Khan, S. H.; Murawski, M. P.; Shenma, J. J. Liq. Chromatogr: $1994,17,855$

10. Thromassin, M.; Cavalli, E.; Guillaume, Y.; Guinchard, C. $J$. Phown. Biomed Anal. 1997, 15, 831.

11. Marengo, E.; Gennaro, M. C.; Gianotti, v. J. Chromatogr: Sci. 2001, 39, 339 .

12. Silva, B. M.; Andrade, P. B.; Mendes, G. C.: Valentao, P.; Seabra, R. M.; Ferreira, M. A.J. Agric. Food Chen. 2000, 48, 2853.

13. Pylypiw, H. M.; Grether, M. T. J. Chronatogr A 2000, 883, 299.

14. Chen, H.; Zno, Y.G; Deng, Y. W. J. Chromatogr. 4 2001, $913,387$.

15. Heinanen, M.; Barbas, C. J. Pharm. Bioned. Anal. 2001, 24, 1005.

16. Gonzalez, M.; Gallego, M.; Valcarcel, M. J. Chromatogr: $A$ 1998, $823,321$.

17. Gonzalez, M.; Gallego, M.; Valcarcel, M. J. Chromatogr: A 1999, $848,529$.

18. De Luca, C.; Passi, S.; Quattrucei, E. Food Addit. Contam. 1995, I?, 1 .

19. Lin, Y. H.; Chou, S. S.; Sheu, F,; Shyu, Y. T. J. Chymatogr: Scr. $2000,38,345$.

20. Frazier, R. A.; Inns, E. L.; Dosis, N.; Ames, J. M.; Mursten, H. E. J. Chromatogr: $A$ 2000, $876,213$.

21. Boyce, M. C. J. Chromatog: $A 1999,847,369$.

22. Pant, I.; Trenerry, V. C. Food Chem. 1995, 53, 219.

23. Andzejewski, D.; Roach, I. A.; Gay, M. L.; Musser, S. M. J. Agric. Food Chem. 2004, 52, 1996.

24. Ono, H.; Chuda, Y.; Ohnishi-Kameyama, M.; Yada, H.; lshizaka, M.; Kobayashi, H.; Yoshido, M. Food Addit. Conton. 2003, 20, 215.

25. Young, M. S.; Jenkins, K. M.; Mallet, C. R. I. AOAC Internutional 2004, 87,961 .

26. Jung, P. G.; Kim, B.; Park, S.-R.; So, H.-Y.; Shi, L.-H.; Kim, Y. Anal. Bioanal. Chent 2004, 380, 782.

27. Park, S.; Kim, B.; So, H.-Y.; Kim, Y.-J.; Kim, J. Bull Korean Chem. Soc. 2007, 28, 737.

28. Jung, M.; Kim, B.; Boo, D.-W.; So, H.-Y. Bull. Korean Chem. Soc. $2007,28,745$. 